\title{
Wave reflection and central pressure augmentation
}

Recently, Cheng et al [1] proposed that central pressure augmentation may be principally determined by left ventricular systolic function rather than vascular wave reflection. We would like to make three comments.

First, we question Cheng et al's interpretation of published work about the role of wave reflection in pressure augmentation. Specifically, [2] and [3] were cited to suggest that the contribution of reflected waves is small or absent in the aorta, while it was stated that [4] "failed to find evidence supporting any predominant effect of wave reflection on pressure augmentation". However,

1) Manisty et al [2] studied carotid (not aortic) waveforms, reported reflection coefficients of $\sim 0.5$ (not small or absent) and stated that "[wave] separation clearly demonstrated that [higher AIx in individuals randomized to atenolol-based rather than amlodipine-based regimen occurred] because of increased wave reflection". It is true that in one example in [2] (Figure 1, right panel), a small forward compression wave labelled ' $\mathrm{c}^{+} 1^{\prime}$ mainly caused the pressure augmentation. Although this wave could conceivably have a direct ventricular origin, it has not been observed in the aorta [5-7] and thus probably arises when reflected waves from elsewhere in the body (e.g. the brachiocephalic artery) are transmitted forwards into the carotid artery [8].

2) The conclusion of Davies et al [3] that augmentation index (AIx) is mainly due to changes in reservoir pressure, not wave reflection, was based on a controversial modification of wave intensity analysis, namely the 'reservoir-wave paradigm', which we have recently shown underestimates actual wave reflection by $40-100 \%$ [9]. Moreover, the view advanced in [3] is moot because, as we [9] and others [10] have pointed out, the reservoir pressure is generated by wave reflection. 
3) Baksi et al [4] concluded that changes in the timing of wave reflection do not account for the increase in systolic blood pressure with age. However, the authors stated that age-related increases in AIx were consistent with marked increases in the magnitude of wave reflection and that their results should not be interpreted as excluding this mechanism [4]. While the discordance between time to the systolic inflection (Ti) and pulse wave velocity (PWV) in [4] might be considered evidence against wave reflection if the aorta were a uniform tube with a discrete distal reflection site, aortic tapering causes distributed wave reflection [11] and a wave 'horizon effect' [5]. In short, the 'reflected wave' arises from a complex series of events that muddies its relation to PWV and Ti. To complicate matters further, the foot of the reflected wave is not reliably estimated by $\mathrm{Ti}[12,13]$.

4) Ample evidence exists that wave reflection underlies aortic pressure augmentation as depicted in Figure 1 of [1]. Without wave reflection, pressure and flow waveforms are identical, and their ratio is equal to characteristic impedance [14]. However, pressure augmentation is accompanied by a decrease in flow [14], a divergence shown by wave separation to be caused by the arrival of a backwardrunning (i.e. reflected) pressure wave $[15,16]$. This view has solid mathematical grounding [14], does not require quasi-periodicity [17], and is supported by invitro [18] and computational studies [9, 13]. Most 'evidence' against wave reflection does not stem from non-validity of wave separation theory, but from unrealistic models of the aorta [11].

Second, we are somewhat puzzled that Cheng et al [1] showed examples of positive AIx in Figures 1 and 2, whereas the carotid and radial artery group data AIx in Figure 3 were negative, as would be expected in young subjects [19]. A negative AIx is thought to be caused by the natural outflow pattern of the left ventricle $[20,21]$, with 
the pressure rise (if any) after Ti indicating wave reflection. Hence, in the absence of wave separation or truly representative pressure waveforms, it is impossible to judge the degree of systolic wave reflection (if any) in the study participants of [1]. While Cheng et al were rightly cautious in extrapolating their conclusions, their data may not be relevant for "question[ing] the prevailing concept of wave reflection as the genesis of the systolic inflection" [1] if study participants exhibited little systolic wave reflection from the outset, as is likely.

Third, although Cheng et al [1] found a weak association between Ti and the time of peak velocity of longitudinal shortening, it is unclear how deceleration of longitudinal shortening could produce a pressure-increasing compression wave (e.g. a $c^{+} 1$ wave [2]) needed to explain a pressure augmentation. One would instead expect this ventricular event to generate a forward expansion (pressuredecreasing) wave related to inertial effects, as explained in [22]. This so-called ' $\mathrm{X}$ ' wave has been found in the aorta [6] and peripheral arteries [2, 8, 22, 23] and is more prominent when AIx is negative. In subjects with negative AIx, one might therefore expect a relation between the times of peak longitudinal shortening and peak pressure (rather than $\mathrm{Ti}$ ) in the aorta. Importantly, though, the $\mathrm{X}$ wave in carotid, brachial and radial arteries probably arises from a different mechanism to the aortic $\mathrm{X}$ wave, namely re-reflection of a primary backward-running reflected wave [23].

Whilst we commend the goal of [1] to explore the contribution of ventricular and vascular phenomena to the central pulse waveform, we suggest that analysis of AIx and $\mathrm{Ti}$ is not the optimal approach because "[positive] augmentation is a manifestation, not a measure of early wave reflection" [24] and, as pointed out in the editorial [25] accompanying [1], AIx is affected by many factors. Wave separation (including 'traditional' wave intensity analysis [9]) remains the gold standard 
technique for investigating features of the pressure waveform [12]. Although uncertainties may exist when interpreting the relatively complex carotid (or more peripheral) arterial wave patterns, aortic wave patterns clearly demonstrate that pressure augmentation is predominantly caused by wave reflection [5-7].

Jonathan P. Mynard ${ }^{1,3}$ and Joseph J. Smolich ${ }^{1,2}$

${ }^{1}$ Heart Research Group, Murdoch Childrens Research Institute and ${ }^{2}$ Department of Paediatrics, University of Melbourne, Melbourne, Australia

${ }^{3}$ Biomedical Simulation Laboratory, University of Toronto, Toronto, Canada

\section{References}

1. Cheng K, Cameron JD, Tung M, Mottram PM, Meredith IT, Hope SA. Association of left ventricular motion and central augmentation index in healthy young men. J Hypertens 2012;30(12):2395-2402.

2. Manisty CH, Zambanini A, Parker KH, Davies JE, Francis DP, Mayet J, et al. Differences in the magnitude of wave reflection account for differential effects of amlodipine- versus atenolol-based regimens on central blood pressure. An AngloScandinavian Cardiac Outcome Trial substudy. Hypertension 2009;54(4):724-730. 3. Davies JE, Baksi J, Francis DP, Hadjiloizou N, Whinnett ZI, Manisty CH, et al. The arterial reservoir pressure increases with aging and is the major determinant of the aortic augmentation index. Am J Physiol Heart Circ Physiol 2010;298(2):H580586.

4. Baksi AJ, Treibel TA, Davies JE, Hadjiloizou N, Foale RA, Parker KH, et al. A meta-analysis of the mechanism of blood pressure change with aging. J Am Coll Cardiol 2009;54(22):2087-2092.

5. Davies JE, Alastruey J, Francis DP, Hadjiloizou N, Whinnett ZI, Manisty CH, et al. Attenuation of wave reflection by wave entrapment creates a "horizon effect" in the human aorta. Hypertension 2012;60(3):778-785.

6. Penny DJ, Mynard JP, Smolich JJ. Aortic wave intensity analysis of ventricular-vascular interaction during incremental dobutamine infusion in adult sheep. Am J Physiol Heart Circ Physiol 2008;294(1):H481-489.

7. Jones CJ, Sugawara M, Kondoh Y, Uchida K, Parker KH. Compression and expansion wavefront travel in canine ascending aortic flow: Wave intensity analysis. Heart Vessels 2002;16(3):91-98.

8. Curtis SL, Zambanini A, Mayet J, McG Thom SA, Foale R, Parker KH, Hughes AD. Reduced systolic wave generation and increased peripheral wave reflection in chronic heart failure. Am J Physiol Heart Circ Physiol 2007;293(1):H557-H562.

9. Mynard JP, Penny DJ, Davidson MR, Smolich JJ. The reservoir-wave paradigm introduces error into arterial wave analysis: A computer modelling and invivo study. J Hypertens 2012;30(4):734-743. 
10. Alastruey J. On the mechanics underlying the reservoir-excess separation in systemic arteries and their implications for pulse wave analysis. Cardiovasc Eng 2010;10(4):176-189.

11. Segers P, Mynard J, Taelman L, Vermeersch S, Swillens A. Wave reflection: Myth or reality? Artery Res 2012;6(1):7-11.

12. Swillens A, Segers P. Assessment of arterial pressure wave reflection:

Methodological considerations. Artery Res 2008;2(4):122-131.

13. Westerhof BE, Westerhof N. Magnitude and return time of the reflected wave: The effects of large artery stiffness and aortic geometry. J Hypertens 2012;30(5):932.

14. Westerhof N, Sipkema P, van den Bos GC, Elzinga G. Forward and backward waves in the arterial system. Cardiovasc Res 1972;6(6):648-656.

15. Laskey WK, Kussmaul WG. Arterial wave reflection in heart failure.

Circulation 1987;75(4):711-722.

16. Murgo JP, Westerhof N, Giolma JP, Altobelli SA. Manipulation of ascending aortic pressure and flow wave reflections with the Valsalva maneuver: Relationship to input impedance. Circulation 1981;63(1):122-132.

17. Parker KH. An introduction to wave intensity analysis. Med Biol Eng Comput 2009;47(2):175-188.

18. Khir AW, Parker KH. Measurements of wave speed and reflected waves in elastic tubes and bifurcations. J Biomech 2002;35(6):775-783.

19. Avolio A. Ageing and wave reflection. J Hypertens 1992;10:S83-S86.

20. Westerhof N, Stergiopulos N, Noble MIM, Stergiopulos N. Wave travel and reflection. In: Snapshots of hemodynamics: Springer US; 2010:147-153.

21. Murgo JP, Westerhof N, Giolma JP, Altobelli SA. Aortic input impedance in normal man: Relationship to pressure wave forms. Circulation 1980;62(1):105-116.

22. Niki K, Sugawara M, Chang D, Harada A, Okada T, Tanaka R. Effects of sublingual nitroglycerin on working conditions of the heart and arterial system:

Analysis using wave intensity. J Med Ultrason 2005;32(4):145-152.

23. Zambanini A, Cunningham SL, Parker KH, Khir AW, Mc GTSA, Hughes

AD. Wave-energy patterns in carotid, brachial, and radial arteries: A noninvasive approach using wave-intensity analysis. Am J Physiol Heart Circ Physiol 2005;289(1):H270-H276.

24. O'Rourke MF, Mancia G. Arterial stiffness. J Hypertens 1999;17(1):1-4.

25. Salvi P, Parati G. Augmentation index as a specific marker of large arteries distensibility: The end of a beautiful tale? J Hypertens 2012;30(12):2276-2278. 


\section{University Library}

\section{- M M I E R R V A gateway to Melbourne's research publications}

Minerva Access is the Institutional Repository of The University of Melbourne

Author/s:

Mynard, JP;Smolich, JJ

Title:

Wave reflection and central pressure augmentation

Date:

2013-04-01

Citation:

Mynard, J. P. \& Smolich, J. J. (2013). Wave reflection and central pressure augmentation. JOURNAL OF HYPERTENSION, 31 (4), pp.841-843. https://doi.org/10.1097/

HJH.0b013e32835ed884.

Persistent Link:

http://hdl.handle.net/11343/58861 